\title{
Predictive factors for functional improvement after intravitreal bevacizumab therapy for macular edema due to branch retinal vein occlusion
}

\author{
Gesine B. Jaissle • Peter Szurman • Nicolas Feltgen • \\ Bernhard Spitzer • Amelie Pielen • Matus Rehak • \\ Georg Spital • Heinrich Heimann • Carsten H. Meyer • \\ Retinal Vein Occlusion Study Group
}

Received: 1 February 2010 /Revised: 15 July 2010 /Accepted: 17 July 2010 /Published online: 18 August 2010

(C) The Author(s) 2010. This article is published with open access at Springerlink.com

\begin{abstract}
Background To identify predictive factors for improvement of visual acuity and central retinal thickness by intravitreal bevacizumab for the treatment of macular edema (ME) due to branch retinal vein occlusion (BRVO).

Methods Two hundred and five eyes from 204 patients with ME secondary to BRVO were retrospectively included at six sites. All eyes received intravitreal bevacizumab therapy $(1.25 \mathrm{mg} / 0.05 \mathrm{ml})$. The mean follow-up was $36.8 \pm 12.7$ weeks (range, 18 to 54 weeks). Measurement of ETDRS bestcorrected visual acuity (BCVA, in all eyes) and optical coherence tomography (OCT, in $87 \%$ of eyes) were performed at baseline and at follow-up examinations every 12 weeks. Using fluorescein angiography, the perfusion status
\end{abstract}

Parts of this work have been presented at the Joint Congress of the Asia Pacific Academy of Ophthalmology and the American Academy of Ophthalmology, Bali, Indonesia, May 2009

G. B. Jaissle $\cdot$ P. Szurman

University Eye Clinic Tuebingen, Centre for Ophthalmology,

Tuebingen, Germany

\section{A. Pielen}

University Eye Hospital Freiburg,

Freiburg, Germany

\section{N. Feltgen}

University Eye Hospital, University of Goettingen,

Goettingen, Germany

\section{B. Spitzer}

Department of Neurology and Bernstein Center for Computational

Neuroscience, Charité University Hospital,

Berlin, Germany

\section{Rehak}

University Eye Hospital, University of Leipzig,

Leipzig, Germany of the macula at baseline could be assessed in $84 \%$ of the eyes. The main outcome measures were changes in BCVA and central retinal thickness (CRT). For analysis of predictive factors, the results at 24 weeks were used.

Results The median BCVA was 0.6 LogMAR at baseline and improved to 0.4 LogMAR at 24 and 48 weeks. This visual improvement was associated by a significant reduction in CRT, decreasing from a baseline of $454 \mu \mathrm{m}$ to $267 \mu \mathrm{m}$ and $248 \mu \mathrm{m}$ after 24 and 48 weeks respectively. Eyes with ME and intact (perfused) or interrupted (ischemic) foveal capillary ring showed a 2-line increase of median BCVA [45 eyes (22\%) and 128 eyes (62\%) respectively]. However, the final median BCVA was significantly worse in eyes with ischemic ME ( 0.6 versus

\section{G. Spital}

Department of Ophthalmology, St. Franziskus Hospital, Muenster, Germany

H. Heimann

St. Paul's Eye Unit, Royal Liverpool University Hospital, Liverpool, UK

C. H. Meyer

Department of Ophthalmology, University of Bonn, Bonn, Germany

G. B. Jaissle ( $\square)$

University Eye Clinic, Centre for Ophthalmology,

Eberhard-Karls University of Tuebingen,

Schleichstr. 12,

72076 Tuebingen, Germany

e-mail: gesine.jaissle@googlemail.com 
$0.3 \operatorname{logMAR}$ in perfused ME). Other factors for visual improvement were absence of previous treatments of the $\mathrm{ME}$, age younger than 60 years and low baseline BCVA $(\geq 0.6 \log \mathrm{MAR})(2,3$, and 2 median BCVA lines increase respectively). Furthermore, eyes with duration of the ME of less than 12 months responded with a 3-line increase of the median BCVA. Final CRT only showed minor differences between the subgroups. During the entire follow-up, retreatments were performed in $85 \%$ of the eyes, with a median number of injections of three (mean 3.2; range, 1 to 10) and a median time-interval between injections of 11.6 weeks (mean 14.6 weeks).

Conclusions Intravitreal injection of bevacizumab resulted in a significant improvement of BCVA and reduction of ME in BRVO. Baseline BCVA, patient's age, and duration of BRVO were found to be of prognostic relevance for visual improvement. A less favorable outcome of the bevacizumab therapy in eyes with longstanding BRVO would advocate initiation of treatment within 12 months after onset.

Keywords Macular edema - Bevacizumab - Branch retinal vein occlusion - Intravitreal therapy · Predictive factors . Prognostic facotrs for visual improvement

\section{Introduction}

Secondary macular edema (ME) is one of the main reasons for loss of visual acuity in branch retinal vein occlusion (BRVO). The randomized, controlled Branch Vein Occlusion Study showed limited treatment benefit in eyes with perfused ME: Grid photocoagulation of the edematous macula resulted in a better visual improvement than in the natural course of the disease [1]. Actually, grid photocoagulation was confirmed as the benchmark in a randomized trial, with $29 \%$ of the eyes gaining 3 or more best corrected visual acuity (BCVA) lines ( $\geq 15$ letters) after 1 year. Intravitreal injection of the corticosteroid triamcinolone acetonide has not been shown to be more effective in BRVO than grid photocoagulation [2] and efficacy of intravitreal pegaptanib therapy is unclear [3]. Also, surgical approaches including vitrectomy with or without peeling of the inner limiting membrane [4], arteriovenous dissection (sheathotomy) [5], laser-induced chorioretinal anastomosis [6], and surgical cannulation of branch retinal veins [7] failed to demonstrate a relevant benefit.

Therefore, a more efficacious treatment strategy has been sought. Bevacizumab (Avastin ${ }^{\circledR}$, Genentech, San Francisco, CA, USA) is a humanized monoclonal antibody directed against the vascular endothelial growth factor (VEGF). The rationale for its intravitreal application in BRVO was that vascular occlusion induces upregulation of VEGF, resulting in increased vascular permeability and subsequent ME 8-10.
Recently, various clinical studies demonstrated beneficial effects of anti-VEGF therapy on both ME and BCVA in patients with BRVO [11-18]. Moreover, this minimally invasive therapy might be even more effective than grid photocoagulation, which is the current standard of care. A prospective study on previously untreated eyes with perfused ME secondary to BRVO demonstrated a gain of 3 or more BCVA lines in $57 \%$ at 1 year [14]. However, the significance of previous studies was limited, due to the relatively small sample sizes. In addition, the optimal time point for initiation of therapy remains unclear. More importantly, there is still minimal knowledge concerning predictive factors for visual outcome.

Because of the large number of patients included, this is the first study to permit a detailed subgroup analysis. This made it possible to investigate various potential predictive factors, including macular perfusion status, duration of the ME, patients' age, baseline BCVA, number of injections applied, and previous treatments before intravitreal bevacizumab therapy in clinical practice.

\section{Subjects and methods}

The study was designed as a multicenter retrospective analysis of patients that received intravitreal bevacizumab therapy for the treatment of BRVO associated with a ME involving the foveal center. Patients received the first bevacizumab injection between October 2005 and May 2009. Only patients that finished the follow-up examination at 24 weeks were included. Eyes that had undergone vitrectomy prior to bevacizumab treatment were excluded due to the different pharmacokinetics. Eyes with other diseases affecting BCVA or presence of neovascularisation were excluded from the analysis. If patients had received peripheral, focal or grid laser photocoagulation, cyclodestructive interventions, cataract surgery, or other surgical procedures during the follow-up they were also excluded.

Baseline examination comprised a complete eye examination, including ETDRS BCVA, slit-lamp biomicroscopy, dilated fundus examination, and optical coherence tomography (OCT) in most eyes. To assess the perfusion status of the macula, preservation (perfused ME) or capillary dropout of the foveal capillary ring (ischemic ME) [1], fluorescein angiographies at baseline were analyzed. In case of hemorrhages in the macular area that obscured the foveal capillary ring, the perfusion status was not evaluated until resorption of these hemorrhages was seen. Only retina specialists experienced in the analysis of fluorescence angiograms were in charge of the analysis in each center.

The study followed the tenets of the Declaration of Helsinki, and was approved by the local ethics committees at each site. 


\section{Intravitreal bevacizumab injection}

The intravitreal injection was performed according to the recommendation of the German Retina Society [19]. The injections were performed after topical anaesthesia and preoperative antisepsis with povidon iodine using sterile gloves, drape, and a lid speculum. Bevacizumab (Avastin ${ }^{\circledR}$ ) $1.25 \mathrm{mg}$ in a $0.05 \mathrm{ml}$ total volume was injected intravitreally via the pars plana. Following the injection, retinal perfusion was controlled.

All patients were informed about the nature of off-label use and the experimental nature of the therapy before signing an informed consent prior to each injection. Also, they confirmed that they were aware of the potential side-effects of bevacizumab treatment. Patients with contraindications against an intravitreal bevacizumab injection (acute ocular infection, recent history of stroke or myocardial infarction, unstable angina pectoris, uncontrolled hypertension, uncompensated renal insufficiency, allergy to bevacizumab, or pregnancy) were excluded from treatment [20].

\section{Follow-up}

Patients were followed on a routine clinical program. Follow-up examinations at 12, 24, 36 and 48 weeks ( \pm 6 weeks) were analyzed. The main outcome measures of this study were BCVA and central retinal thickness (CRT) as measured by OCT (Stratus $\mathrm{OCT}^{\mathrm{TM}}$, Carl Zeiss Meditec, Jena, Germany, axial tissue resolution $10-15 \mu \mathrm{m}$, or Spectralis ${ }^{\circledR}$ OCT, Heidelberg Engineering, Dossenheim, Germany, axial tissue resolution $4 \mu \mathrm{m}$ ). To minimize variability between different devices, all patients were followed up with the same OCT. CRT was calculated as the distance between the inner limiting membrane and the retinal pigment epitheliumchoriocapillaris interface of radial lines through the foveal area [21]. The foveal area was determined using the patient's fixation and retinal landmarks. The calipers were set by hand because automated measurement protocols are more prone to errors [22]. For comparison, the normal CRT in healthy eyes was reported to be $170 \pm 18 \mu \mathrm{m}[23]$.

Re-injection was considered at each follow-up visit, and performed after informed consent of the patient, depending on the individual course of the BCVA and persistence or reoccurence of ME on OCT.

\section{Statistics}

VA data were converted to $\log$ MAR units before analysis. All continuous variables (BCVA and CRT) were described as box plots showing 5\% and 95\% quantiles (whiskers), $25 \%$ and $75 \%$ quartiles (box), and the median (marked by an asterisk). While conventional statistical inference in this study is based on sample means, we use median values as a robust index of the sample's central tendency for descriptive report of the data.

The following prognostic variables were studied: perfusion status of the foveal capillary ring (ischemic or perfused), existence of pre-treatment, patients' age (younger than 60 years or 60 years and older), duration of BRVO ( $<3$ months, 3 to 12 months, or $>12$ months), baseline BCVA (0.6 logMAR and lower or $0.5 \log$ MAR and higher), number of injections applied (one, two or three and more), gender (male or female), and presence of arterial hypertension.

Overall differences in VA and CRT at 0, 12, and 24 weeks were assessed using repeated measures analysis of variance (ANOVA). Subgroup-specific changes in VA and CRT were analyzed using paired $t$-tests (two-sided). Significant prognostic factors for an increase in VA were identified by between-subjects multifactorial ANOVA and Tukey's HSD post-hoc tests where appropriate. Further differences between subgroups were analyzed using unpaired $t$-tests, and between-subjects ANOVAs in the case of more than two subgroups. To control for multiple comparisons, Bonferroni correction was applied with respect to the overall number of tests for VA and CRT differences respectively (VA: eight tests, CRT: eight tests), resulting in adjusted significance thresholds of $p=0.00625$ All statistical analysis was performed using SPSS 16 (SPSS Inc, Chicago, IL, USA).

\section{Results}

This multicenter, retrospective interventional case series enrolled 205 eyes (204 patients) of six centres that were treated with intravitreal bevacizumab due to ME secondary to BRVO. Patient characteristics at baseline are shown in Table 1. The median follow-up was 36.7 weeks (range, 18 to 54 weeks; mean $36.8 \pm 12.7$ weeks). The median age of the patients was 69 years (range, 38 to 87 years). The bevacizumab treatment resulted in a significant improvement of the median BCVA (ANOVA $p<0.001$ ), increasing from 0.6 $\log$ MAR at baseline to $0.5 \log$ MAR at 12 weeks and $0.4 \log$ MAR at 24 weeks (both $p^{\prime}<0.001$ ). Ninety-one eyes $(44.4 \%)$ finished the final follow-up examination at 48 weeks. They showed a maintenance of the median BCVA of $0.4 \log$ MAR corresponding to a total improvement of 2 median BCVA lines compared to baseline ( $p<$ 0.001 , Fig. 1a). OCT data were available in $91 \%, 82 \%$, and $87 \%$ of all eyes at baseline, 12 , and 24 weeks, respectively. Accordingly, reduction of the CRT was highly significant with the median CRT (ANOVA $p<$ 0.001 ) decreasing from a baseline of $454 \mu \mathrm{m}$ to $304 \mu \mathrm{m}$ and $267 \mu \mathrm{m}$ after 12 and 24 weeks, respectively (both $p<$ 0.001). This significant reduction was preserved over the 
Table 1 Predictive factors for visual improvement (at 24 weeks)

\begin{tabular}{llllll}
\hline Factor & $\begin{array}{l}\text { Number } \\
\text { of eyes }\end{array}$ & $\begin{array}{l}\text { Increase of } \\
\text { median }\end{array}$ & $\begin{array}{l}P \text { value } \\
\text { (increase) }\end{array}$ & $\begin{array}{l}\text { Final } \\
\text { median } \\
\text { BCVA lines }\end{array}$ & $\begin{array}{l}\text { ANOVA } \\
(p \\
\end{array}$ \\
& & & $\begin{array}{l}\text { BCVA } \\
\text { (logMAR) }\end{array}$ & value) \\
\hline
\end{tabular}

\begin{tabular}{cccccc}
\hline Gender & \multicolumn{3}{c}{0.83} \\
Male & $\begin{array}{l}101 \\
(49 \%)\end{array}$ & 2 & $<0.001 *$ & 0.4 & \\
Female & $\begin{array}{l}104 \\
\text { (51\%) }\end{array}$ & 2 & $<0.001 *$ & 0.4 & \\
Hypertension \\
Yes & 131 & 2 & & & 0.89 \\
No & $(64 \%)$ & & $<0.001 *$ & 0.4 & \\
& 69 & 2 & $<0.001 *$ & 0.4 &
\end{tabular}

Perfusion status of the macula

$$
\begin{array}{rll}
\text { Ischemic } & 45 & 2 \\
& (22 \%) & \\
\text { Perfused } & 128 & 2 \\
& (62 \%) & \\
\text { Pretreatment } &
\end{array}
$$

$\begin{array}{lll}\text { Yes } & 26 & 0.5 \\ & (13 \%) & \\ \text { No } & 176 & 2 \\ & (86 \%) & \end{array}$

Patients' age (years)

$\begin{array}{lll}<60 & 41 & 3 \\ & (20 \%) & \\ \geq 60 & 163 & 1 \\ & (80 \%)\end{array}$

Baseline BCVA (logMAR)

$\begin{array}{lll}\leq 0.5 & 91 & 1 \\ & (44 \%) & \\ \geq 0.6 & 114 & 2 \\ & (56 \%) & \end{array}$

Duration of BRVO (months)

$\begin{array}{lllll}<3 & 63 & 2.5 & <0.001 * & 0.3 \\ 3-12 & (31 \%) & & & \\ & 71 & 2 & <0.001 * & 0.4 \\ >12 & (35 \%) & & & \\ & \begin{array}{l}60 \\ (29 \%)\end{array} & 0.5 & <0.01 & 0.5\end{array}$

Number of injections

$\begin{array}{lllll}1 & 46 & 2.5 & <0.001 * & 0.35 \\ & (22 \%) & & & \\ 2 & 79 & 2 & <0.001 * 0.5 \\ & (39 \%) & & & \\ \geq 3 & 74 & 2 & <0.001 * 0.4 \\ & (36 \%) & & & \end{array}$

$*$ = Significant difference (Bonferroni-corrected)

$+=$ Post-hoc test (Tukey-HSD): $<3$ months and $>12$ months sign. difference)

entire follow-up with a final median CRT of $248 \mu \mathrm{m}$ at 1 year (63 eyes, $p<0.001$, Fig. $1 b)$. During the follow-up, a median of three injections (mean 3.2; range, 1 to 10) was administered, with a median injection frequency of 11.6 weeks (mean 14.6 weeks).

\section{Analysis of predictive factors}

Because BCVA and CRT did not significantly change between 24 and 48 weeks (Fig. 1a,b), analysis of predictive factors was performed on the basis of the 24 weeks results of all 205 eyes included.

Evaluation of the perfusion status of the macular area revealed an ischemic ME with a broken foveal capillary ring in 22\% (45 eyes) and a perfused ME in 62\% (128 eyes). Sufficient information on the perfusion status was not available in $16 \%$ (32 eyes) (Table 1). Interestingly, both subgroups with perfused and ischemic ME improved 2 median BCVA lines at 24 weeks (both $p<0.001$ ). However, eyes with an ischemic ME started from a lower median baseline BCVA of $0.8 \log$ MAR compared to $0.5 \log$ MAR of the subgroup with a perfused ME $(p<0.001)$. Hence, their final median BCVA of $0.6 \log$ MAR at 24 weeks was significantly lower than $0.3 \log$ MAR in eyes with a perfused ME $(p<0.001)$ (Fig. 2a). Comparing the baseline and final median CRT in the two subgroups, there was no
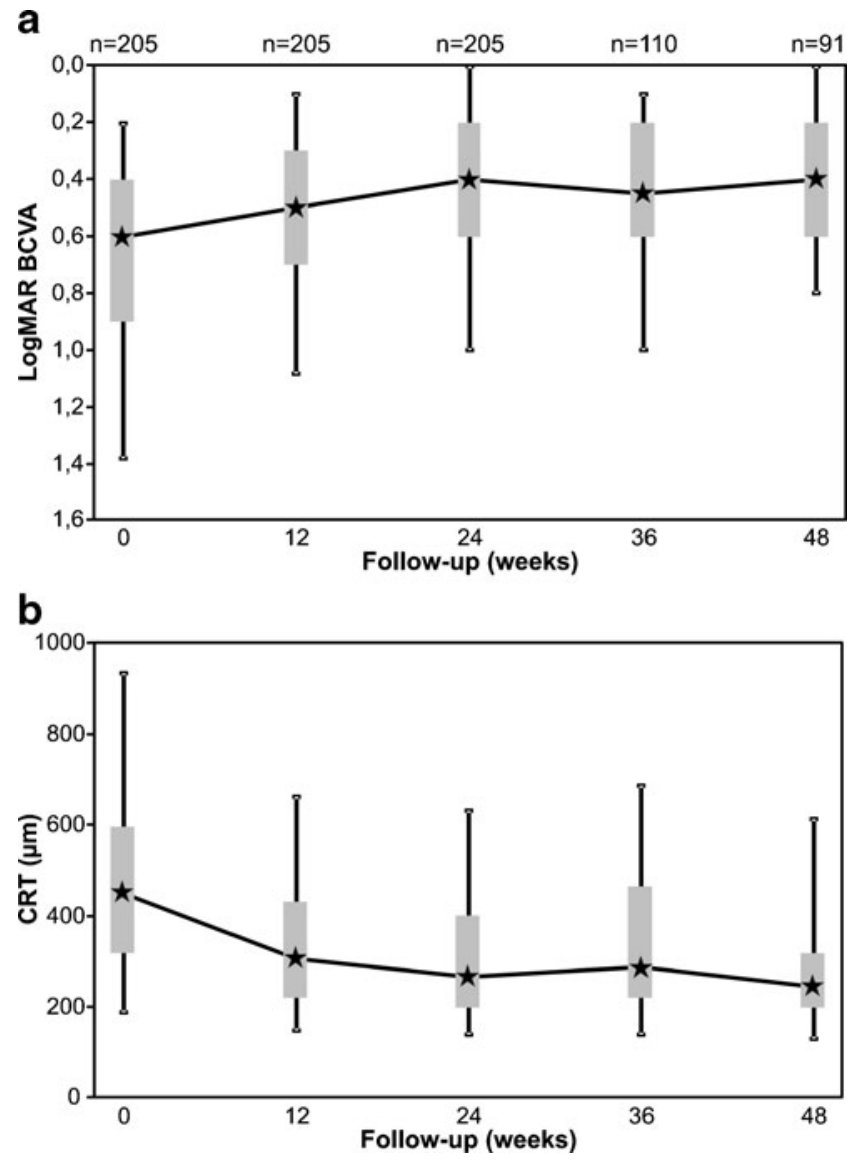

Fig. 1 Box plot graphs showing the course of best-corrected visual acuity (BCVA) (a) and central retinal thickness (CRT) (b) over the 48 weeks follow-up. a Increase of BCVA, and $\mathbf{b}$, decrease of the CRT following bevacizumab treatment. Note the stabilisation after 24 weeks. $n=$ number of eyes included 

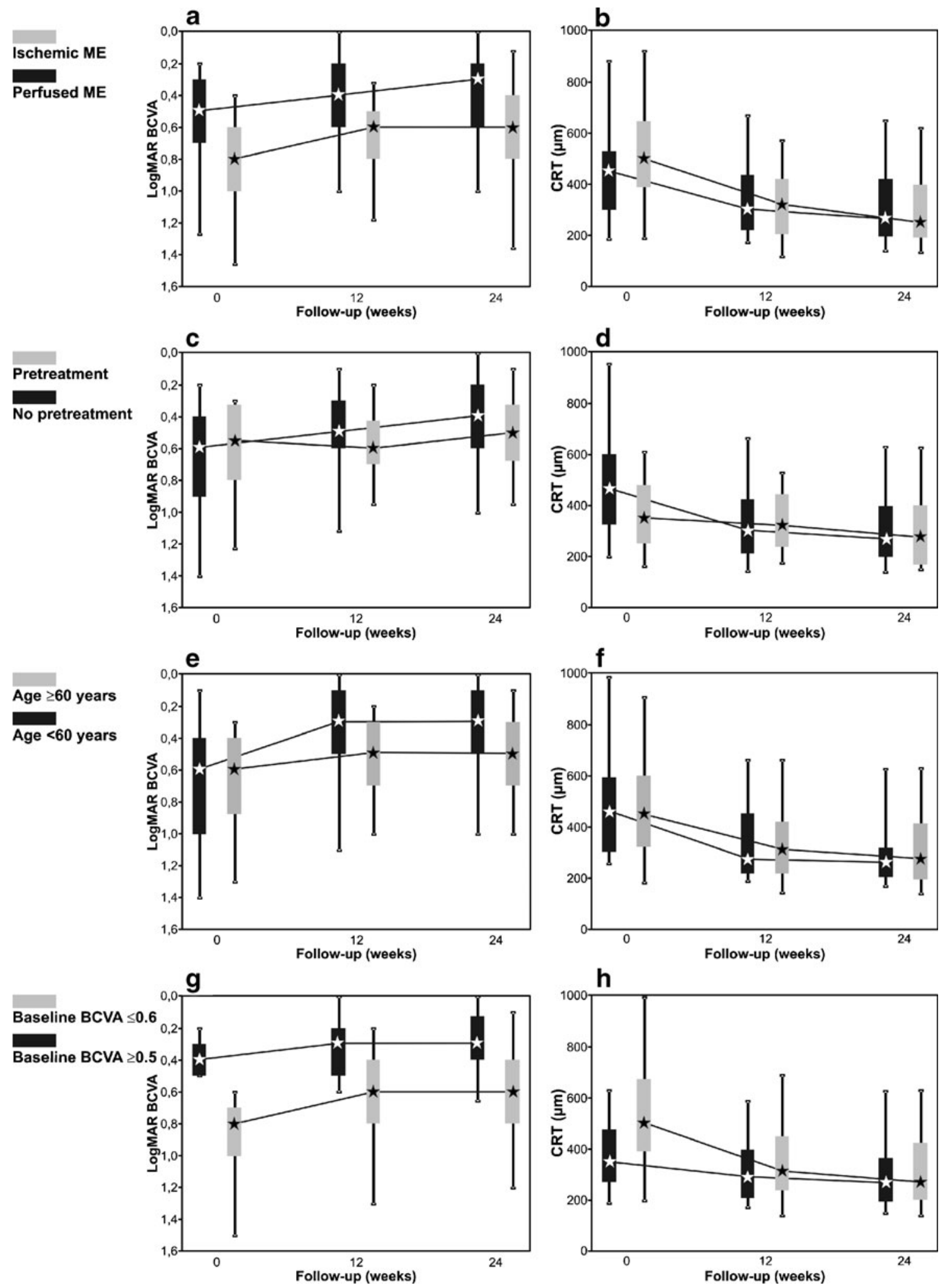

Fig. 2 Box plot graphs showing the bevacizumab effect depending on the duration of the perfusion status of the macula $(\mathbf{a}, \mathbf{b})$, on the existence of pretreatment $(\mathbf{c}, \mathbf{d})$, on the patients' age $(\mathbf{e}, \mathbf{f})$, and on the baseline visual acuity (VA) (g, h) during the 24 weeks follow-up. Left column demonstrates the course of the BCVA, the right column shows the central retinal thickness (CRT) 
significant difference between the subgroup with ischemic and perfused ME (baseline: $500 \mu \mathrm{m}$ and $450 \mu \mathrm{m}(p=0.04$, n.s.); 24 weeks: $266 \mu \mathrm{m}$ and $250 \mu \mathrm{m}(p=0.44$, n.s. $)$ respectively) (Fig. 2b).

Pretreatment had been undertaken in 13\% (26 eyes); 23 eyes had undergone grid laser photocoagulation, and seven eyes had received intravitreal triamcinolone injection prior to bevacizumab treatment. Eighty-six percent (176 eyes) received bevacizumab as a primary therapy for BRVO (Table 1). Interestingly, the pretreated subgroup only showed a visual improvement of 0.5 median BCVA lines from a median of $0.55 \log$ MAR to $0.5 \log$ MAR at 24 weeks $(p<0.005$, Fig. $2 \mathrm{c})$, and no reliable decrease of the median CRT from $350 \mu \mathrm{m}$ at baseline to $274 \mu \mathrm{m}$ at 24 weeks ( $p=$ 0.113 , Fig. 2 d). In contrast, the previously untreated eyes responded with a 2-line increase of the median BCVA (0.6 $\log$ MAR to $0.4 \log$ MAR, $p<0.001$, Fig. $2 c$ ), together with a reduction of the CRT (463 $\mu \mathrm{m}$ to $266 \mu \mathrm{m}, p<0.001$, Fig. 2d). The duration of the BRVO-associated symptoms was significantly longer in the pretreated subgroup, with 21.4 months versus 4.3 months in previously untreated eyes $(p<0.005)$.

Analysis of the patients' age at the time of BRVO confirmed it as a significant prognostic factor for gain in BCVA (multi-factorial ANOVA, $p<0.001$ ), with a better response in younger individuals (Table 1). The subgroup of patients who were younger than 60 years of age (41 eyes, $20 \%$ ) revealed a considerable 3-line increase of the median BCVA (from 0.6 logMAR at baseline to $0.3 \log$ MAR at 24 weeks, $p<0.001)$. In contrast, patients of 60 years and older (163 eyes, $80 \%$ ) only showed a gain of 1 median BCVA line (from $0.6 \log$ MAR at baseline to $0.5 \log$ MAR at 24 weeks), which was statistically significant, $p<0.001$, Fig. 2e). This is despite the fact that the median CRT of younger and older patients was not significantly different, neither at baseline ( $463 \mu \mathrm{m}$ compared to $350 \mu \mathrm{m}, p=0.86$ ), nor at 24 weeks $(260 \mu \mathrm{m}$ compared to $275 \mu \mathrm{m}, p=0.70)$ (Fig. 2f). However, the median duration of BRVO prior to bevacizumab therapy was significantly shorter in younger individuals (3.0 months; range, 0.0 to 75 months) than in older individuals ( 6.5 months; range, 0.0 to 163 months) ( $p<$ 0.05 ). Moreover, in the younger subgroup, only $5 \%$ (two eyes) had received pretreatment (intravitreal triamcinolone injection), compared to $15 \%$ (24 eyes) in the older subgroup.

To investigate the prognostic value of the baseline BCVA, the eyes were divided into two subgroups with a $\mathrm{BCVA} \geq 0.6 \log \mathrm{MAR}$ (range: 0.6 to $2.0 \log$ MAR, 114 eyes) and $\leq 0.5 \log$ MAR (range, 0.1 to $0.5 \log$ MAR, 91 eyes) before treatment. Our data showed that eyes with a low baseline BCVA gained median 2 BCVA lines (from 0.8 $\log$ MAR to $0.6 \log$ MAR, $p<0.001$ ), whereas eyes with a high initial BCVA only gained median 1 VA line (from 0.4 $\log$ MAR to $0.3 \log$ MAR, $p<0.001$ ) (Fig. 2g). Multi- factorial ANOVA confirmed baseline BCVA as a significant prognostic factor for BCVA gain $(p<0.001$, Table 1$)$. Comparing the percentage of ischemic ME and hemorrhage in the foveal area in the two subgroups, both were considerably higher in the cohort with a low baseline BCVA ( $32 \%$ and $37 \%$ versus $10 \%$ and $17 \%$ ). Also, the median baseline CRT was higher in eyes with a low initial BCVA compared to eyes with a high initial BCVA $(501 \mu \mathrm{m}$ versus $348 \mu \mathrm{m}, p<0.001)$. However, both subgroups improved their median CRT at 24 weeks to comparable levels ( $270 \mu \mathrm{m}$ and $266 \mu \mathrm{m}$ respectively, $p=0.43)$ (Fig. $2 \mathrm{~h}$ )

The median time between the onset of BRVO-associated symptoms and the baseline examination was 5.7 months (range, 0.0 to 163 months). The onset of BRVO-associated symptoms remained unclear in 5\% (11 eyes) (Table 1). To evaluate the impact of early treatment on BCVA and ME, the eyes were assigned to one of three subgroups according to the duration of BRVO prior bevacizumab therapy: group A $<3$ months (63 eyes), group B 3 to 12 months ( 71 eyes), and group $\mathrm{C}>12$ months ( 60 eyes). Multi-factorial ANOVA confirmed duration of BRVO-associated symptoms as a significant prognostic factor for BCVA gain $(p=0.03)$, with a significantly higher gain for group A than for group $\mathrm{C}$ $(p<0.05$, Tukey HSD). Interestingly, subgroup A showed a significant gain of 2.5 median BCVA lines from a median baseline of $0.65 \operatorname{logMAR}$ to $0.3 \log$ MAR at 24 weeks $(p<0.001)$, whereas the visual improvement in group B was 2 median BCVA lines (from 0.6 to $0.4 \log$ MAR, $p<0.001$ ). In contrast, subgroup $\mathrm{C}$ only showed a 0.5 line increase of the median BCVA, from 0.55 to $0.5 \log$ MAR at 24 weeks $(p=0.005)$ (Fig. 3a). Hemorrhage in the foveal area at baseline was present in $45 \%$ (28 eyes) of group A, in 34\% (24 eyes) of group B, and in 7\% (four eyes) of group C. With regard to the median CRT at 24 weeks, there was no significant difference between the three groups (A $273 \mu \mathrm{m}$, B $260 \mu \mathrm{m}$, and C $290 \mu \mathrm{m}, p=0.86)$ even though at baseline significant differences were evident (ANOVA $p<0.05$ ); Baseline CRT was significantly higher in group A, $483 \mu \mathrm{m}$ compared to $400 \mu \mathrm{m}$ in group $\mathrm{C}(p<0.05$ Tukey HSD) and $472 \mu \mathrm{m}$ in group B, Fig. 3b).

To maintain the bevacizumab effect until week 24 , reinjections were performed in $75 \%$ (153 eyes). During the 6-month follow-up, a median of two injections (mean 2.3; range, 1 to 6) was administered, with a median timeinterval between injections of 11.5 weeks (mean 14.8 weeks). The relationship between the bevacizumab effect and the number of injections was analyzed, assigning the eyes to a subgroup with one, two or three and more injections. Interestingly, the BCVA showed comparable results in all three subgroups, with an increase of the median BCVA of 2.5 lines (one injection) or 2 lines (two and $\geq 3$ injections) (ANOVA $p=0.27$, Fig. $3 \mathrm{c}$ ). When comparing the median CRT at baseline and at 24 weeks 

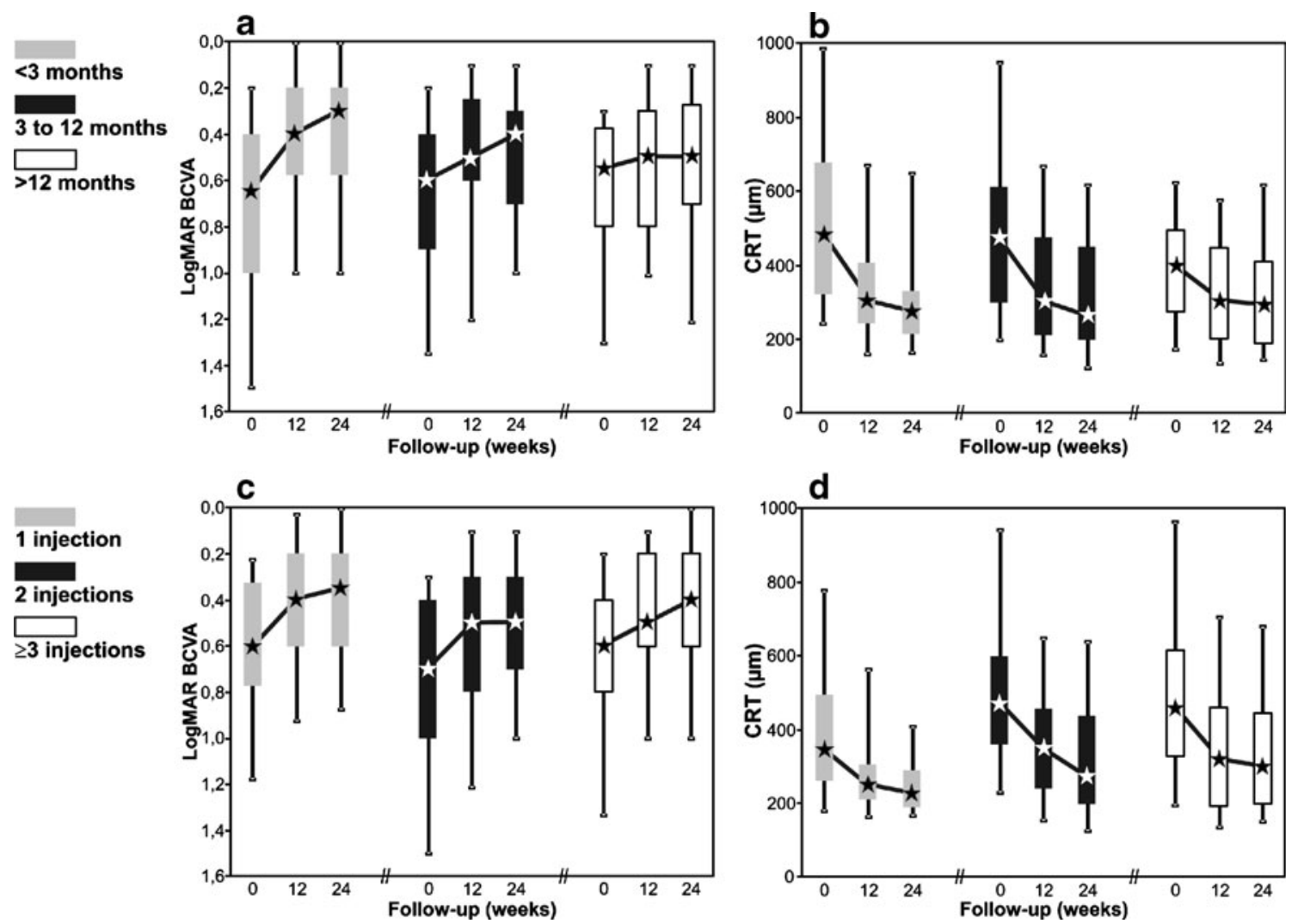

Fig. 3 Box plot graphs showing the bevacizumab effect depending on the duration of the BRVO-associated symptoms $(\mathbf{a}, \mathbf{b})$, and on the number of injections applied (c, d) during the 24 weeks follow-up.

between the three subgroups, they were lowest in the subset with only one injection ( 345 and $224 \mu \mathrm{m}$ ), and increased with more injections (two injections: 472 and $271 \mu \mathrm{m}$; three and more injections: 454 and $296 \mu \mathrm{m}$, both ANOVA $p<0.05$ ) (Fig. 3d). For the group of three or more injections (74 eyes) we analysed if there is a correlation between the number of injections and BCVA or CRT. However, the analysis revealed no significant correlation $(p>0.05)$, neither for BCVA nor for CRT.

As the number of eyes included in the analysis varied across parameters (from 173 to 205, Table 1) we performed an additional analysis on a subset of eyes where the complete data of all essential parameters (perfusion status of the macula, pretreatment, patients' age, baseline BCVA, duration of BRVO, and number of injections) was available. This subset of eyes included 158 eyes. Comparably, multifactorial ANOVA confirmed patients' age $(p<0.001)$, baseline BCVA $(p<0.001)$, and duration of macular edema ( $p=$ $0.05)$ as significant prognostic factors for BCVA gain (Table 2).

As eyes with central glaucomatous visual field defects and diabetic maculopathy were excluded from our study, the percentage of eyes with glaucoma and diabetes $(7 \%$ and $10 \%$, respectively) was likely to be underestimated,
Left column demonstrates the course of the visual acuity (VA), the right column shows the central retinal thickness (CRT)

and therefore was not part of the analysis of predictive factors.

No cases of endophthalmitis, retinal detachment or any other severe procedure-related complications were observed in a total of 652 injections. No obvious bevacizumabrelated ocular or systemic adverse events were reported.

\section{Discussion}

This multicentre study examined the anatomic and functional long-term effectiveness of bevacizumab therapy on ME secondary to BRVO in a routine clinical setting. Previously, several prospective studies have shown a significant 3-line increase of BCVA together with a reduction of ME [14-16]. Our study shows that comparable results can also be obtained in the clinical routine. In this large patient cohort, a significant increase of the median BCVA of 2 lines was achieved at the 6-month follow-up, and could be maintained through the 1-year follow-up.

Together with results from other reported studies, intravitreal bevacizumab may appear as an established treatment for ME secondary to BRVO [14, 18]. However, clinical practice has also revealed that some patients respond better 
Table 2 Predictive factors for visual improvement at 24 weeks (subgroup of 157 eyes)

\begin{tabular}{|c|c|c|c|c|c|}
\hline Factor & $\begin{array}{l}\text { Number } \\
\text { of eyes }\end{array}$ & $\begin{array}{l}\text { Increase of } \\
\text { median } \\
\text { BCVA lines }\end{array}$ & $\begin{array}{l}P \text { value } \\
\text { (increase) }\end{array}$ & $\begin{array}{l}\text { Final } \\
\text { Median } \\
\text { BCVA } \\
\text { (logMAR) }\end{array}$ & $\begin{array}{l}\text { ANOVA } \\
(p \\
\text { value })\end{array}$ \\
\hline \multicolumn{5}{|c|}{ Perfusion status of the macula } & 0.97 \\
\hline Ischemic & $\begin{array}{l}40 \\
(25 \%)\end{array}$ & 3 & $<0.001 *$ & 0.6 & \\
\hline Perfused & $\begin{array}{l}117 \\
(75 \%)\end{array}$ & 1 & $<0.001 *$ & 0.4 & \\
\hline \multicolumn{5}{|c|}{ Pretreatment } & 0.86 \\
\hline Yes & $\begin{array}{l}21 \\
(13 \%)\end{array}$ & 0 & $=0.018$ & 0.5 & \\
\hline No & $\begin{array}{l}136 \\
(87 \%)\end{array}$ & 2 & $<0.001 *$ & 0.4 & \\
\hline \multicolumn{5}{|c|}{ Patients' age (years) } & $\begin{array}{l}<0.001 \\
*\end{array}$ \\
\hline$<60$ & $\begin{array}{l}33 \\
(21 \%)\end{array}$ & 3 & $<0.001 *$ & 0.3 & \\
\hline$\geq 60$ & $\begin{array}{l}124 \\
(79 \%)\end{array}$ & 1 & $<0.001 *$ & 0.5 & \\
\hline \multicolumn{5}{|c|}{ Baseline BCVA (logMAR) } & $\begin{array}{l}<0.001 \\
*\end{array}$ \\
\hline$\leq 0.5$ & $\begin{array}{l}68 \\
(43 \%)\end{array}$ & 1 & $=0.029$ & 0.3 & \\
\hline$\geq 0.6$ & $\begin{array}{l}89 \\
(57 \%)\end{array}$ & 2 & $<0.001 *$ & 0.6 & \\
\hline \multicolumn{5}{|c|}{ Duration of BRVO (months) } & $0.05 *+$ \\
\hline$<3$ & $\begin{array}{l}50 \\
(32 \%)\end{array}$ & 2.5 & $<0.001 *$ & 0.35 & \\
\hline $3-12$ & $\begin{array}{l}54 \\
(34 \%)\end{array}$ & 2 & $<0.001 *$ & 0.4 & \\
\hline$>12$ & $\begin{array}{l}53 \\
(34 \%)\end{array}$ & 1 & $=0.011$ & 0.5 & \\
\hline \multicolumn{5}{|c|}{ Number of Injections } & 0.34 \\
\hline 1 & $\begin{array}{l}41 \\
(26 \%)\end{array}$ & 1 & $<0.001 *$ & 0.5 & \\
\hline 2 & $\begin{array}{l}62 \\
(40 \%)\end{array}$ & 2 & $<0.001 *$ & 0.5 & \\
\hline$\geq 3$ & $\begin{array}{l}54 \\
(34 \%)\end{array}$ & 2 & $=0.001 *$ & 0.4 & \\
\hline
\end{tabular}

$*$ = Significant difference (Bonferroni-corrected)

$+=$ Post-hoc test (Tukey-HSD): no significant pair-wise differences

than others, while factors for the variability in outcomes have been controversial. Due to the large sample size, this is the first study that allows analyzing potential predictive factors in detail to pre-estimate the effectiveness of the therapy.

A point of intense debate is the influence of the perfusion status of the macula on treatment outcomes. While the beneficial effect of bevacizumab in eyes with $\mathrm{ME}$ and perfused foveal capillary ring seems to be generally acknowledged, concerns have been raised on bevacizumab treatment in ischemic ME $[8,24]$. Also, grid photocoagulation has not been recommended for BRVO with foveal capillary nonperfusion [1].
Our study was able to demonstrate for the first time that existence of an ischemic ME can still be associated with an excellent response to bevacizumab therapy. These eyes showed both a pronounced reduction of the CRT and a considerable visual improvement of 2 lines, comparable to the visual improvement in eyes with perfused ME. This interesting finding seems to be in contrast to previous studies. Chung et al. reported the presence of macular ischemia as a significant negative factor for BCVA improvement. The investigation was done on 50 eyes subdivided into two groups $(\geq 1$ BCVA line gain vs $<1$ BCVA line gain) [25]. However, analysis in our cohort revealed BCVA gain in about $70 \%$ of the eyes in both ischemic (69\%) and perfused ME (73\%), indicating a potential for BCVA improvement in ischemic ME.

How can we explain the apparent discrepancy between the significant BCVA gain in eyes with ischemic macular edema and the clinical observation that these patients rarely achieve a satisfactory post-treatment BCVA? One should take into account that eyes with ischemic ME disclose a low baseline BCVA, which prevents most eyes to achieve reading visual acuity even if the treatment response is good. Irreversible structural changes induced by persisting hypoxia in the centre of the macula have been identified as the reason behind this observation [8]. Patient satisfaction is not solely determined by gain in BCVA line, but rather by achieving useful vision. Hence, many patients with ischemic ME remain disappointed despite the remarkable 2-line gain. On the other hand, patients with perfused ME seem to be more satisfied with a 2-line BCVA gain because of the high rate of reading ability achieved.

Another important question addresses the optimal time point for initiation of bevacizumab therapy. The Branch Vein Occlusion Study showed a worse BCVA outcome in eyes where the treatment with grid laser photocoagulation had been performed more than 1 year after onset of the BRVO [1]. Comparable findings have been described for intravitreal bevacizumab therapy $[12,16]$. Our study confirmed these results showing no significant visual improvement in longstanding ME of more than 1 year. Photoreceptor damage as a result of chronic ME has been proposed to explain the irreversible BCVA impairment [8].

In contrast, eyes with duration of BRVO shorter than 1 year showed a 2-line BCVA increase. Moreover, further shortening of the initiation of therapy resulted in a further improvement of the outcome. Here, a very early treatment ( $<3$ months) revealed an increase of 2.5 BCVA lines and a remarkable final BCVA of $0.3 \log$ MAR. This might indicate some irreversible damage to the macula following delayed treatment, which has also been proposed by Kondo and colleagues [18]. However, absorption of hemorrhages in the foveal area that are frequently apparent in the subgroup of very early treatment might be a cofactor for the 
good recovery. Also, spontaneous recovery in the early course of the disease independent of the bevacizumab effect might play a significant role.

In addition to the duration of BRVO, the patient's age has been identified as a prognostic factor. We were able to demonstrate that patients under 60 years of age respond with a 3-line increase of BCVA. Additionally, these eyes develop a high final BCVA of $0.3 \log$ MAR. However, in the younger subgroup the median duration of BRVO was shorter, and fewer eyes had undergone pretreatment, accounting for a better bevacizumab response. However, a correlation of age and BCVA has also been found recently by a prospective study [17]. On the other hand, patient age of 60 years and older was associated with minor visual improvement, despite a comparable reduction of the CRT. One might conclude from these data that the anatomical response does not seem to be an appropriate clinical tool for evaluating the treatment benefit. Eyes with poor prognostic factors develop a poor visual outcome, despite the fact that these eyes often show a marked reduction of CRT.

Baseline BCVA has also been identified as a predictive factor for visual improvement. In accordance with previous studies [18], we found a poor baseline BCVA $(>0.5$ $\log$ MAR) to be correlated with poor visual prognosis below reading BCVA. Frequent associations with a poor baseline BCVA were presence of an ischemic ME and hemorrhage in the foveal area. Vice versa, a good initial BCVA $(\leq 0.5$ $\operatorname{logMAR}$ ) was significantly associated with a good visual outcome. In contrast to previous findings [24], our study demonstrates a remarkable visual improvement of 2 BCVA lines in eyes with a poor baseline, even exceeding the visual improvement in eyes with a high initial BCVA. A negative correlation of preoperative VA and improvement of VA has also been shown in a current study [18]. The pronounced reduction of the CRT in patients with low baseline BCVA compared to eyes with high baseline BCVA is in accordance with the findings of Kriechbaum and colleagues [16].

Existence of pretreatment has been identified as a negative factor for visual improvement. Eyes with a persistent ME after pretreatment responded with no significant increase of the BCVA to the bevacizumab treatment, despite an excellent reduction of the CRT. However, as pretreatment was correlated with very longstanding ME, this might also account for a worse treatment effect. Due to the small sample number, our results are limited, though a reduced prognosis for BCVA improvement and final BCVA in pretreated eyes was also described in previous studies [11, 15].

Another question that is frequently raised addresses the number of re-injections needed to maintain the treatment effect. In our study, we found a mean injection rate of 2.3 injections within 6 months and a mean of 3.2 during the entire follow-up. A prospective study recently reported similar injection rates, with a mean of 2.6 and 3.4 injections within the first 6 or 12 months respectively, resulting in an increase of 3 BCVA lines [14]. Taking into account the fact that our current study has been performed on a clinical routine basis that did not adhere to strict retreatment criteria, and even included eyes with pretreatment and long-standing ME, the current results are remarkably comparable.

Is a more frequent re-injection rate beneficial? Another prospective study performed an OCT-guided treatment regime with a mean of eight injections during a 12-month follow-up, which resulted in a 3.5-line increase in BCVA [13]. This indicates that a higher injection rate above a critical level does not result in a further increase of the treatment effect. Accordingly, we could not find a better visual improvement with increased numbers of bevacizumab injections. Our study rather demonstrates a slightly higher final median CRT despite frequent re-injections indicating non-responders.

One of the most notable results of our study concerns the effect of bevacizumab on the ME. Independent of the median baseline CRT of all subgroups $(345 \mu \mathrm{m}$ to $501 \mu \mathrm{m})$, and independent of the bevacizumab effect on the BCVA, the treatment resulted in a decrease of the CRT to a median CRT ranging from 224 to $296 \mu \mathrm{m}$ (250 to $275 \mu \mathrm{m}$ except for the subgroups with duration of BRVO of more than 12 months, and number of injections of one and three or more) at 6 months. This indicates that the effect of bevacizumab on the ME is not a reduction by a certain percentage, but rather a decrease to a defined median CRT around $260 \mu \mathrm{m}$. Therefore, it appears necessary to adjust the re-injection rate to the individual course of the BCVA and CRT on OCT.

Main limitations of this study were the retrospective character, the inconsistent reinjection criteria, and the absence of a control group. The drawback of the variable number of eyes across parameters included in the subgroup analysis was counterbalanced by the second subgroup analysis with a homogeneous data set revealing basically comparable results. However, a prospective, randomized study is needed to further assess the effectivity of bevacizumab on various subgroups. However, this is the first study with a sufficient number of patients included to permit the identification of predictive factors in a routine clinical treatment setting.

Based on more than 650 intravitreal injections in this study, no concerns on the safety of the drug emerged. This is especially important in view of the off-label use and the necessity for repeated injections in most eyes.

As duration of the BRVO of more than 1 year seems to result in a negligible effect of bevacizumab, earlier treatment initiation might be reasonable. This study data 
could be important for understanding the effect of bevacizumab on BCVA and ME, and to manage individual treatment regimes for eyes with BRVO.

Open Access This article is distributed under the terms of the Creative Commons Attribution Noncommercial License which permits any noncommercial use, distribution, and reproduction in any medium, provided the original author(s) and source are credited.

\section{Appendix}

Retinal Vein Occlusion Study Group (in alphabetical order): Hansjürgen Agostini ${ }^{2}$, MD, Karl Ulrich Bartz-Schmidt ${ }^{1}$, MD, Spyridon Dimopoulos ${ }^{1}, \mathrm{MD}$, Anastasia Dimopoulou ${ }^{1}$, MD, Nicolas Feltgen ${ }^{3}$, MD, Faik Gelisken ${ }^{1}$, MD, Lutz Lothar Hansen ${ }^{2}$, MD, Heinrich Heimann ${ }^{7}$, MD, Frank $\mathrm{Holz}^{8}, \mathrm{MD}$, Gesine B Jaissle ${ }^{1}, \mathrm{MD}$, Martin Leitritz ${ }^{1}, \mathrm{MD}$, Carsten $\mathrm{H}_{\text {Meyer }}^{8}$, MD, Amelie Pielen ${ }^{2}$, MD, Matus Rehak $^{5}$, MD, Georg Spital ${ }^{6}, \mathrm{MD}$, Bernhard Spitzer ${ }^{4}, \mathrm{MD}$, Peter Szurman ${ }^{1}$, MD, Peter Wiedemann ${ }^{5}$, MD

\section{References}

1. The Branch Vein Occlusion Study Group (1984) Argon laser photocoagulation for macular edema in branch vein occlusion. Am J Ophthalmol 98:271-282

2. The SCORE Study Research Group (2009) A randomized trial comparing the efficacy and safety of intravitreal triamcinolone with standard care to treat vision loss associated with macular edema secondary to branch retinal vein occlusion: the standard care vs corticosteroid for retinal vein occlusion (SCORE) study report 6. Arch Ophthalmol 127:1115-1128

3. Wroblewski JJ, Wells JA 3rd, Gonzales CR (2010) Pegaptanib sodium for macular edema secondary to branch retinal vein occlusion. Am J Ophthalmol 149(1):147-154

4. Mandelcorn MS, Nrusimhadevara RK (2004) Internal limiting membrane peeling for decompression of macular edema in retinal vein occlusion: a report of 14 cases. Retina 24:348355

5. Mester U, Dillinger P (2002) Vitrectomy with arteriovenous decompression and internal limiting membrane dissection in branch retinal vein occlusion. Retina 22:740-746

6. Fekrat S, Goldberg MF, Finkelstein D (1998) Laser-induced chorioretinal venous anastomosis for nonischemic central or branch retinal vein occlusion. Arch Ophthalmol 116:43-52

7. Weiss JN, Bynoe LA (2001) Injection of tissue plasminogen activator into a branch retinal vein in eyes with central retinal vein occlusion. Ophthalmology 108:2249-2257

8. Noma H, Funatsu H, Yamasaki M, Tsukamoto H, Mimura T, Sone T, Hirayama T, Tamura H, Yamashita H, Minamoto A, Mishima HK (2008) Aqueous humour levels of cytokines are correlated to vitreous levels and severity of macular oedema in branch retinal vein occlusion. Eye 22:42-48

9. Funk M, Kriechbaum K, Prager F, Benesch T, Georgopoulos M, Zlabinger GJ, Schmidt-Erfurth U (2009) Intraocular concentrations of growth factors and cytokines in retinal vein occlusion and the effect of therapy with -bevacizumab. Investig Ophthalmol Vis Sci 50:1025-1032
10. Krohne TU, Eter N, Holz FG, Meyer CH (2008) Intraocular pharmacokinetics of bevacizumab after a single intravitreal injection in humans. Am J Ophthalmol 146:508-512

11. Rabena MD, Pieramici DJ, Castellarin AA, Nasir MA, Avery RL (2007) Intravitreal bevacizumab (Avastin) in the treatment of macular edema secondary to branch retinal vein occlusion. Retina 27:419-425

12. Rensch F, Jonas JB, Spandau UH (2008) Early intravitreal bevacizumab for non-ischaemic branch retinal vein occlusion. Ophthalmologica 223:124-127

13. Prager F, Michels S, Kriechbaum K, Georgopoulos M, Funk M, Geitzenauer W, Polak K, Schmidt-Erfurth U (2009) Intravitreal bevacizumab (Avastin) for macular edema secondary to retinal vein occlusion - twelve-month results of a prospective clinical trial. Br J Ophthalmol 93:452-526

14. Jaissle GB, Leitritz M, Gelisken F, Ziemssen F, Bartz-Schmidt KU, Szurman P (2009) One-year results after intravitreal bevacizumab therapy for macular edema secondary to branch retinal vein occlusion. Graefes Arch Clin Exp Ophthalmol 247:27-33

15. Kreutzer TC, Alge CS, Wolf AH, Kook D, Burger J, Strauss R, Kunze C, Haritoglou C, Kampik A, Priglinger S (2008) Intravitreal bevacizumab for the treatment of macular oedema secondary to branch retinal vein occlusion. Br J Ophthalmol 92:351-355

16. Kriechbaum K, Michels S, Prager F, Georgopoulos M, Funk M, Geitzenauer W, Schmidt-Erfurth U (2008) Intravitreal Avastin for macular oedema secondary to retinal vein occlusion: a prospective study. Br J Ophthalmol 92:518-522

17. Stahl A, Agostini H, Hansen LL, Feltgen N (2007) Bevacizumab in retinal vein occlusion-results of a prospective case series. Graefes Arch Clin Exp Ophthalmol 245:1429-1436

18. Kondo M, Kondo N, Ito Y, Kachi S, Kikuchi M, Yasuma TR, Ota I, Kensaku M, Terasaki H (2009) Intravitreal injection of bevacizumab for macular edema secondary to branch retinal vein occlusion: results after 12 months and multiple regression analysis. Retina 29:1242-1248

19. Jaissle GB, Szurman P, Bartz-Schmidt K (2005) Recommendation for the procedure of intravitreal injections of the German Retina Society, the German Society of Ophthalmology (DOG) and the German Professional Association of Ophthalmologists (BVA). Klin Monatsbl Augenheilkd 222:390-395

20. Jaissle GB, Karl I, Bartz-Schmidt KU (2008) Einwilligung und Besonderheiten der Aufklärung im Off-Label-Bereich. In: BartzSchmidt KU, Ziemssen F (eds) Intravitreale Pharmakotherapie. Moderne Medikamente und ihre Anwendung am Auge. Schattauer, Stuttgart, pp 25-29

21. Sadda SR, Wu Z, Walsh AC, Richine L, Dougall J, Cortez R, LaBree LD (2006) Errors in retinal thickness measurements obtained by optical coherence tomography. Ophthalmology 113:285-293

22. Bolz M, Ritter M, Polak K, Bolz M, Ritter M, Polak K, Ahlers C, Hirn C, Prünte C, Golbaz I, Benesch T, Schmidt-Erfurth U (2008) The role of stratus OCT in anti-VEGF therapy: qualitative and quantitative assessment of neovascular AMD. Ophthalmologe 105:650-655

23. Chan A, Duker JS, Ko TH, Fujimoto JG, Schuman JS (2006) Normal macular thickness measurements in healthy eyes using stratus optical coherence tomography. Arch Ophthalmol 124:193-198

24. Glacet-Bernard A, Coscas G, Chabanel A, Zourdani A, Lelong F, Samama MM (1996) Prognostic factors for retinal vein occlusion: prospective study of 175 cases. Ophthalmology 103:551-560

25. Chung EJ, Hong YT, Lee SC, Chung EJ, Hong YT, Lee SC, Kwon OW, Koh HJ (2008) Prognostic factors for visual outcome after intravitreal bevacizumab for macular edema due to branch retinal vein occlusion. Graefes Arch Clin Exp Ophthalmol 246:1241-1247 